\title{
Genetic aspects of fibrodysplasia ossificans progressiva
}

\author{
J M CONNOR AND D A P EVANS
}

From the Department of Medicine, Royal Liverpool Hospital, PO Box 147, Liverpool L69 $3 B X$

SUMmaRY Complete ascertainment of fibrodysplasia ossificans progressiva in the United Kingdom was attempted and 44 patients were identified. This indicates a point prevalence of $0.61 \times 10^{-6}$. The disease is determined as an autosomal dominant trait which has complete penetrance but variable expressivity. No evidence for genetic heterogeneity was found in this series. All patients represented fresh gene mutations and their biological fitness was zero. Geographical clustering of these new mutations was evident but conformed to the general population distribution. The direct estimate of the mutation rate was $1.8(\mathrm{SE} \pm 1 \cdot 04) \times 10^{-6}$ mutations per gene per generation. A significant paternal age effect was evident for these new mutations in the United Kingdom.

Fibrodysplasia ossificans progressiva (FOP), also known as myositis ossificans progressiva, is a rare autosomal dominant disorder in which there is progressive ossification of the connective tissue of voluntary muscles and ligaments in addition to characteristic skeletal malformations. ${ }^{1}$ A paternal age effect on the occurrence of new mutations in this disease has been suggested by two investigations, one from Germany ${ }^{2}$ and one from the USA. ${ }^{3}$ The present investigation sought to confirm this in FOP patients from the UK and also to determine the prevalence and mutation rates.

\section{Methods of ascertainment}

Complete ascertainment was attempted by a variety of techniques which included: a national consultant survey, a survey of disabled homes and associations, computer searches of HAA (Hospitals Activity Analysis) records, and a computer search of death certificates. The consultant survey was sent in 1979 to 2152 consultants throughout the UK and included those who were most likely to be involved in the care of a patient with FOP. A total of $80 \%$ (1723) replied: orthopaedic surgeons 617 of $750(82 \%)$; radiologists 521 of $719(72 \%)$; paediatricians 397 of $459(86 \%)$; histopathologists 172 of $208(83 \%)$; clinical geneticists 10 of 10; and metabolic physicians 6 of 6 . A total of 133 potential patients was notified. The other lines of approach yielded three further potential patients. Home visits were then arranged to confirm the diagnosis in the probands and to examine their relatives.

Received for publication 27 April 1981

\section{Results}

Ninety of the notifications related to 44 FOP patients from the UK. The rest either related to foreign patients with the disease or to other diseases which cause ectopic calcification or ossification. Of the 44 probands, seven whose records confirmed the diagnosis could not be traced and three had died many years ago. Thirty-four probands were thus traced and examined. In addition, 44 of 68 parents, 40 of 128 sibs, and all other relatives who were considered to have any stigmata of FOP were examined physically (by JMC).

These FOP patients had an equal sex ratio and an age range of 4 to 70 years (mean $28 \cdot 0, S D_{116} \cdot 1$ ). Twenty-five of the 34 were 16 years of age or older and 30 of these 34 patients are still alive (in 1981). Four have died since the investigation began. These deaths were: at 34 years of pneumonia; in her late twenties, unknown cause; at 32 years of pneumonia; and at 57 years of pneumonia and partial atlantoaxial subluxation. Thirty of the patients were alive in England and Wales in mid-1978 out of a total estimated population of $49117300 .{ }^{4}$ The point prevalence was therefore $0.61 \times 10^{-6}$. This figure does not include the seven patients who could not be traced and thus might be a slight underestimate.

All patients had disabling ectopic ossification in addition to characteristic skeletal malformations. The latter included: short monophalangic big toes $(79 \%$, figs 1,2$)$; rigid big toes $(15 \%)$; reduction defects of all digits $(6 \%)$; short first metacarpals $(59 \%$, fig 3$)$; fifth finger clinodactyly $(44 \%)$; short broad femoral necks (55\%); upper tibial exostoses, 
and abnormal cervical vertebrae. A more detailed account of these clinical features will be published separately.

No proband had an affected relative although five first degree relatives (four females and one male) had unrelated primary hallux valgus. Thus, all probands in this series represented fresh FOP mutations. None

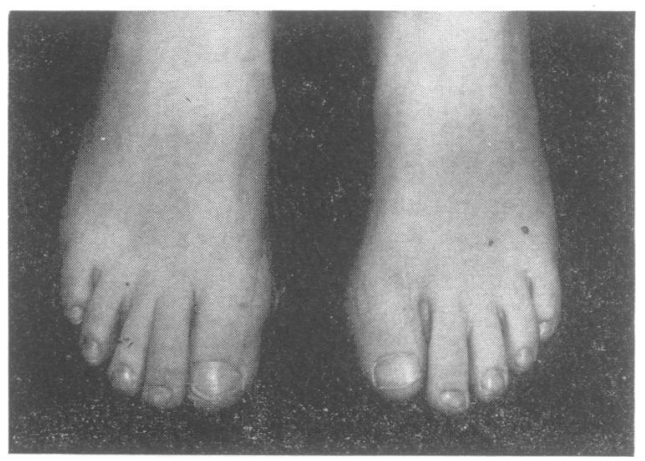

FIG 1 Shortened big toes in FOP

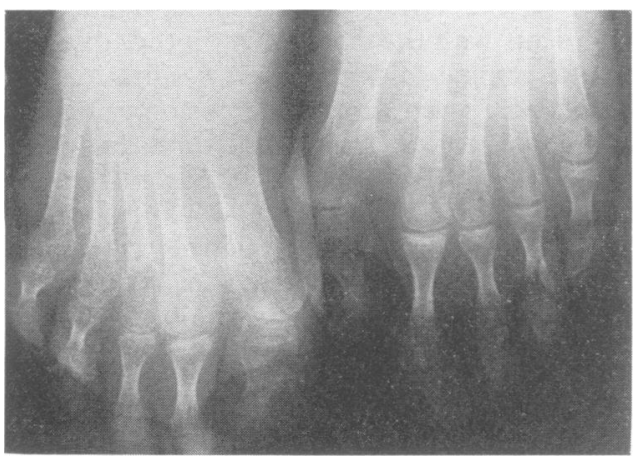

FIG 2 Monophalangic big toes in FOP

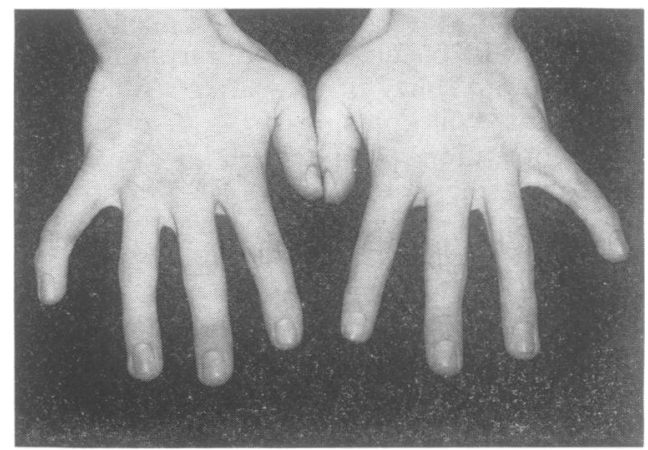

FIG 3 Short first metacarpals and fifth finger clinodactyly in FOP

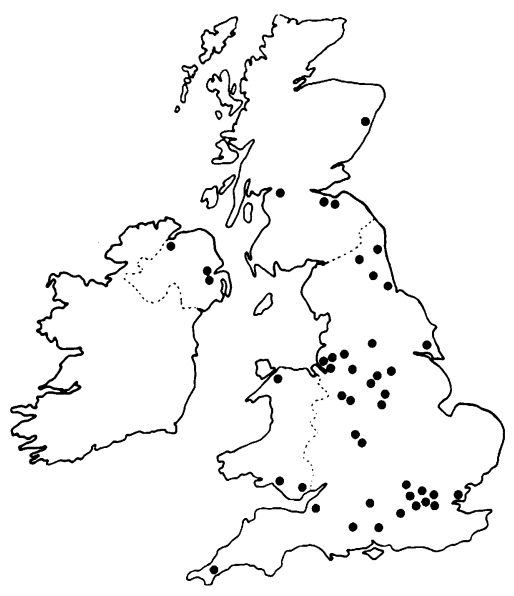

FIG 4 Geographical distribution of new FOP mutations according to place of birth

of these patients had reproduced. Fig 4 shows the geographical distribution of these new FOP mutations according to place of birth. Clustering of these new mutations was evident but conformed to the 1951 population distribution as a whole. ${ }^{5}$

TABLE 1 Parental ages and birth order for 33 new FOP mutations in the United Kingdom

\begin{tabular}{|c|c|c|c|}
\hline $\begin{array}{l}\text { Year of birth } \\
\text { of patient }\end{array}$ & $\begin{array}{l}\text { Father's age } \\
\text { at birth }(y r)\end{array}$ & $\begin{array}{l}\text { Mother's age } \\
\text { at birth }(y r)\end{array}$ & $\begin{array}{l}\text { Birth } \\
\text { order }\end{array}$ \\
\hline $\begin{array}{l}1910 \\
1920 \\
1920 \\
1922 \\
1929 \\
1936 \\
1940 \\
1940 \\
1944 \\
1947 \\
1947 \\
1947 \\
1949 \\
1949 \\
1950 \\
1951 \\
1952 \\
1952 \\
1953 \\
1954 \\
1955 \\
1956 \\
1960 \\
1960 \\
1963 \\
1965 \\
1965 \\
1970 \\
1971 \\
1972 \\
1973 \\
1973 \\
1976\end{array}$ & $\begin{array}{l}40 \cdot 82 \\
36 \cdot 11 \\
36 \cdot 37 \\
31 \cdot 82 \\
31 \cdot 32 \\
41 \cdot 28 \\
30 \cdot 5 \\
38 \cdot 74 \\
34 \cdot 64 \\
40 \cdot 22 \\
34 \cdot 43 \\
39 \cdot 1 \\
31 \cdot 29 \\
53 \cdot 78 \\
38 \cdot 42 \\
39 \cdot 75 \\
26 \cdot 92 \\
31 \cdot 59 \\
31 \cdot 0 \\
29 \cdot 15 \\
27 \cdot 54 \\
36 \cdot 26 \\
37 \cdot 72 \\
54 \cdot 66 \\
34 \cdot 0 \\
29 \cdot 45 \\
31 \cdot 86 \\
31 \cdot 62 \\
26 \cdot 36 \\
29 \cdot 52 \\
42 \cdot 42 \\
25 \cdot 06 \\
32 \cdot 0\end{array}$ & $\begin{array}{l}37 \cdot 53 \\
40 \cdot 1 \\
33 \cdot 38 \\
32 \cdot 6 \\
28 \cdot 02 \\
35 \cdot 16 \\
27 \cdot 37 \\
37 \cdot 24 \\
25 \cdot 45 \\
35 \cdot 81 \\
29 \cdot 84 \\
32 \cdot 77 \\
21 \cdot 65 \\
32 \cdot 48 \\
36 \cdot 62 \\
36 \cdot 82 \\
25 \cdot 96 \\
25 \cdot 68 \\
29 \cdot 0 \\
26 \cdot 04 \\
29 \cdot 97 \\
35 \cdot 35 \\
31 \cdot 5 \\
29 \cdot 49 \\
27 \cdot 17 \\
24 \cdot 99 \\
32 \cdot 18 \\
26 \cdot 49 \\
25 \cdot 46 \\
27 \cdot 01 \\
26 \cdot 49 \\
25 \cdot 26 \\
30 \cdot 71\end{array}$ & $\begin{array}{r}7 \\
4 \\
5 \\
4 \\
4 \\
11 \\
2 \\
1 \\
2 \\
9 \\
2 \\
1 \\
1 \\
2 \\
1 \\
5 \\
3 \\
2 \\
2 \\
2 \\
2 \\
6 \\
3 \\
4 \\
2 \\
2 \\
1 \\
3 \\
4 \\
2 \\
2 \\
1 \\
3\end{array}$ \\
\hline
\end{tabular}


TABLE 2 Comparison of FOP and general population parental age and birth order data

\begin{tabular}{|c|c|c|c|c|c|c|}
\hline & $\begin{array}{l}\text { Mean paternal } \\
\text { age }(y r)\end{array}$ & Difference & $\begin{array}{l}\text { Mean maternal } \\
\text { age }(y r)\end{array}$ & Difference & $\begin{array}{l}\text { Mean birth } \\
\text { order }\end{array}$ & Difference \\
\hline $\begin{array}{l}\text { UK new FOP mutations } \\
\text { England and Wales, } 1951 \\
\text { England and Wales, } 1961 \\
\text { Australia , } 1953^{7} \\
\text { London, 19528 }\end{array}$ & $\begin{array}{l}35 \cdot 02 \\
S D \pm 6 \cdot 797 \\
\\
30 \cdot 17 \\
S D \pm 6 \cdot 68 \\
31 \cdot 04 \\
S D \pm 6 \cdot 79 \\
30 \cdot 3\end{array}$ & $\begin{array}{l}4.85 \\
p<0.001 \\
3.98 \\
p<0.01 \\
4.72 \\
p<0.001\end{array}$ & $\begin{array}{l}30 \cdot 35 \\
\text { SD } \pm 4 \cdot 639 \\
27 \cdot 99 \\
S D \pm 5 \cdot 93 \\
27 \cdot 09 \\
S D \pm 5 \cdot 8\end{array}$ & $\begin{array}{l}2 \cdot 36 \\
\mathrm{p}<0.01 \\
3 \cdot 26 \\
\mathrm{p}<0.001\end{array}$ & $\begin{array}{l}3 \cdot 18 \\
S D \pm 2 \cdot 324 \\
2 \cdot 26 \\
S D \pm 1 \cdot 57 \\
2 \cdot 28 \\
S D \pm 1 \cdot 54\end{array}$ & $\begin{array}{l}0.92 \\
\mathrm{p}<0.05 \\
0.9 \\
\mathrm{p}<0.05\end{array}$ \\
\hline
\end{tabular}

The mutation rate was estimated for the Merseyside conurbation. During the period 1940 to 1971 three new FOP mutations were identified out of 835000 livebirths. This gives a direct estimate of the mutation rate of $1 \cdot 8(\mathrm{SE} \pm 1 \cdot 04) \times 10^{-6}$ mutations per gene per generation.

None of the parents was consanguineous. For 33 of the FOP probands full parental age and birth order data were available and are given in table 1. The birth order was based on the number of children born to the mother regardless of sire, and none of these families is contemplating further offspring. The method of Haldane and Smith ${ }^{6}$ compares the sum of the observed birth orders multiplied by six (6A) with its expected value. If the observed exceeds the expected by more than twice its standard error then a significant excess of persons of high birth order are present in the observations. For the FOP data $6 \mathrm{~A}$ exceeded its expected value by 153 or 3.35 times its standard error $(p<0 \cdot 001)$.

The mean values for parental ages at the time of birth and birth order for the FOP data are given in table 2. Control population data for maternal age and birth order were calculated from the Registrar General's Report for England and Wales for 1951 (the mean year of birth of the FOP patients). Paternal age data were not collected for the UK until 1961 and so the Australian mean paternal age figure $^{7}$ for 1953 and a London figure for $1952^{8}$ are also given. Comparison of these means with the $t$ test showed that all of the FOP means were significantly raised from the control values.

Analysis by the method of Smith ${ }^{9}$ uses multiple linear regression to provide values for the direct effect of each of the three variables: paternal age, maternal age, and birth order. It also provides a standard error for each of these values, and if any of the direct estimates exceed twice the standard error then this is statistically significant. For the FOP data the estimate of direct paternal age effect $\left(d_{f}\right)$ was $4 \cdot 74(2 \mathrm{SE}=4 \cdot 579)$. The value for direct maternal age effect $\left(\mathrm{d}_{\mathrm{m}}\right)$ was $-2 \cdot 29(2 \mathrm{SE}=$
4.028) and for direct birth order effect $\left(d_{b}\right)$ was $0.89(2 \mathrm{SE}=0.976)$.

\section{Discussion}

The results show a highly significant excess of high birth order among these new FOP mutations. The method of Smith ${ }^{9}$ showed that the direct paternal age effect exceeded twice its standard error and was thus statistically significant, whereas no significant direct effect was detected for maternal age or birth order. There have been two previous studies ${ }^{2} 3$ on this aspect of FOP, and their results are compared with those of the present investigation in table 3 . In all three investigations the mean parental ages and birth order were significantly raised in comparison with appropriate control groups. Tünte $e t a^{2}$ also showed an excess of high birth order using the method of Haldane and Smith, ${ }^{6}$ and Rogers and Chase $^{3}$ found a significant direct effect only for paternal age with the method of Smith, ${ }^{9} d_{f}=2 \cdot 87$ (2 $\mathrm{SE}=2 \cdot 82), \mathrm{d}_{\mathrm{m}}=0.77(2 \mathrm{SE}=2 \cdot 96)$, and $\mathrm{d}_{\mathrm{b}}=$ $0.37(2 \mathrm{SE}=0.62)$.

In all such studies the choice of appropriate control data is important, as parental ages and birth order are liable to change with time in various ethnic groups. Tünte et $a^{2}$ compared data on German FOP patients plus data from published cases with a

TABLE 3 Comparison of FOP parental age and birth order data in different countries

\begin{tabular}{|c|c|c|c|}
\hline & $\begin{array}{l}\text { Mean paternal } \\
\text { age }(y r)\end{array}$ & $\begin{array}{l}\text { Mean maternal } \\
\text { age }(y r)\end{array}$ & $\begin{array}{l}\text { Mean birth } \\
\text { order }\end{array}$ \\
\hline $\begin{array}{l}\text { Tünte et al, } 2 \\
\text { Germany } \\
\text { Rogers and } \\
\text { Chase, }{ }^{3}\end{array}$ & $37 \cdot 2(\mathrm{SD} \pm 7 \cdot 2)$ & $31 \cdot 6(\mathrm{SD} \pm 6 \cdot 0)$ & $3 \cdot 2(\mathrm{SD} \pm 2 \cdot 0)$ \\
\hline $\begin{array}{l}\text { USA } \\
\text { Present study } \\
\text { (1981), } \\
\text { United } \\
\text { Kingdom }\end{array}$ & $\begin{array}{l}32 \cdot 9(\mathrm{SD} \pm 7 \cdot 6) \\
35 \cdot 0(\mathrm{SD} \pm 6 \cdot 8)\end{array}$ & $29 \cdot 3(\mathrm{SD} \pm 6 \cdot 0)$ & $3 \cdot 2\left(\mathrm{SD}_{ \pm 2} \cdot 3\right)$ \\
\hline
\end{tabular}


mixed reference population from England, Denmark, Norway, and Japan. Rogers and Chase $^{3}$ used US Census data for their control values but their survey included patients outside the USA. In the present investigation, appropriate control data were available for maternal age and birth order but the 1953 Australian figure of 31.04 years had to be used for mean paternal age. This, however, is probably appropriate as $\mathrm{Krooth}^{8}$ quoted a mean paternal age figure of 30.3 years in 1952 for a series of births in London. The UK data thus support the conclusion that increased paternal age is the most important factor in the occurrence of new FOP mutations.

A paternal age effect has been demonstrated in a number of other autosomal dominant disorders. ${ }^{710} 11$ It is believed to reflect the pattern of germ cell maturation in the male. In the male there is a continuous division of the primitive stem cells. ${ }^{12}$ Thus, an initial stem cell mutation would produce an accumulation of mutant genes in the stem cell pool. The spermatozoa are derived from spermatogonia from this pool, and so with increasing age the chance of fertilisation by a sperm which carries the mutant gene will increase. If this is the case then the actual mutation rate is not increasing with age, only the proportion of sperms which carry the original mutation. This does not, however, explain the cause of the original mutation.

Autosomal dominant inheritance of FOP is generally accepted ${ }^{12}$ on the basis of two sets of concordant monozygotic twins ${ }^{1314}$ and several instances of parent-to-child transmission, including male-to-male transmission. ${ }^{15} 16$ Occasionally, one of the parents of a child with FOP has had only the characteristic skeletal malformations. ${ }^{17}$ No patient in either the present series or in the previous largest personally evaluated series of Tünte $e t a l^{2}$ had such a minimally affected parent, although several in both series had a relative with unrelated primary hallux valgus. No patient in the present series had reproduced although most had reached reproductive age and all except one had developed normal secondary sexual characteristics. Few FOP patients have reproduced ${ }^{15-17}$ and thus the biological fitness appears to be close to zero. Physical disability is probably the main reason for such a low fitness but infertility may also be involved. ${ }^{2}$

Although lifespan appears to be reduced in FOP, most patients in this series have already reached adult life. Some authors ${ }^{18}{ }^{19}$ have proposed that the majority of patients with FOP die before 15 years of age. The present study would clearly not support this conclusion. Survival to the fourth decade is probably usual in FOP but definitive data on this point will only be available when all in the present unselected series have died. Pneumonia, predisposed to by chest wall fixation, has been the usual terminal event, both in published reports and in the present series. ${ }^{20}$

There is no evidence, either from published reports or the present investigation, that the FOP gene is ever non-penetrant. For if this were the case, and the patient had normal fertility, then instances of affected sibs with normal parents would have been expected. The gene does, however, have variable expressivity with regard to the extent of both the skeletal malformations and the ectopic ossification. This variable expression could account for the observed phenotypic variation in FOP and genetic heterogeneity need not be invoked.

The present investigation has also provided the first estimates for the prevalence and mutation rates of FOP. Mair ${ }^{18}$ could find only three cases of FOP in Britain in 1925 and stated that there were none in a series of 130000 children at schools for the physically handicapped in London. The direct estimate for the mutation rate of $1.8 \times 10^{-6}$ mutations per gene per generation is comparable to those reported for other disorders such as aniridia $\left(4 \times 10^{-6}\right.$ mutations per gene per generation $\left.{ }^{21}\right)$ and the Marfan syndrome $\left(5 \times 10^{-6}\right.$ mutations per gene per generation $^{22}$ ). The geographical distribution of new FOP mutations showed clustering but this clustering conformed to the population distribution as a whole. This probably accounts for the clustering rather than any direct geographical effect on the mutation rate. If the estimated mutation rate is close to the actual rate then, at equilibrium, with a biological fitness of close to zero, two or three new FOP patients should be born per year in the UK.

The genetic counsellor should examine the parents of an affected child to exclude the characteristic skeletal malformations of FOP. They can then be reassured of a negligible recurrence risk. If the potential father is over 50 years of age then the risk is probably seven-fold that of a father of 30 years, but even in this case the actual recurrence risk is extremely low. For an affected person with FOP, either fully or minimally expressed, each child would have a one in two chance of receiving the FOP gene and developing the disease. In this situation demonstration of the abnormal big toes by fetoscopy might offer the prospect of selective termination.

This study was undertaken while one of us (JMC) had tenure of a University Research Fellowship with the University of Liverpool. We wish to thank the consultants throughout the UK who have cooperated in this investigation. 


\section{References}

1 McKusick VA. Heritable disorders of connective tissue. 4th ed. St Louis: Mosby, 1972.

2 Tünte W, Becker PE, von Knorre GV. Zur Genetik der Myositis ossificans progressiva. Humangenetik 1967;4: 320-51.

3 Rogers JG, Chase GA. Paternal age effect in fibrodysplasia ossificans progressiva. J Med Genet 1979;16: 147-8.

4 OPCS Monitor. Mid-1978 population estimates for health areas (reference PP1 79/6). London: Office of Population Censuses and Surveys, 1979.

5 Bickmore DP, Derry TK. Concise Oxford atlas. 2nd ed. London: Oxford University Press, 1958.

6 Haldane JBS, Smith CAB. A simple exact test for birthorder effect. Ann Eugen 1947;14:117-24.

7 Blank CE. Apert's syndrome (a type of acrocephalosyndactyly): observations on a British series of thirty-nine cases. Ann Hum Genet 1960;24:151-64.

8 Krooth RS. The aetiology of human malformations. PhD thesis, University of London, 1952.

9 Smith CAB. Note on the estimation of parental age effects. Ann Hum Genet 1972; 35:337-42.

10 Murdoch JL, Walker BA, McKusick VA. Parental age effect on the occurrence of new mutations for the Marfan syndrome. Ann Hum Genet 1972;35:331-6.

11 Jones KL, Smith DW, Sedgwick Harvey MA, Hall BD, Quan L. Older paternal age and fresh gene mutation: data on additional disorders. $J$ Pediatr 1975;86:84-8.
12 Clermont Y. Renewal of spermatogonia in man. Am J Anat 1966;118:509-24.

13 Eaton WL, Conkling WS, Daeschner CW. Early myositis ossificans progressiva occurring in homozygotic twins. A clinical and pathologic study. J Pediatr 1957;50:591-8.

14 Vastine JH, Vastine MF, Arango O. Myositis ossificans progressiva in homozygotic twins. AJR 1948;59:204-12.

15 Burton-Fanning FW, Vaughan AL. A case of myositis ossificans. Lancet $1901 ;$ ii:849-50.

16 Gaster A. Discussion in meeting in West London Medico-Chirurgical Society, 7 October 1904. West London Medical Journal 1905:10:37.

17 Sympson T. Case of myositis ossificans. Br Med $\mathrm{J}$ 1886 ;ii: $1026-7$.

18 Mair WF. Myositis ossificans progressiva. Edinburgh Med J 1932;39:13-36, 69-92.

19 Rosenstirn J. A contribution to the study of myositis ossificans progressiva. Ann Surg 1918;68:485-520, 591637.

20 Connor JM, Evans CC, Evans DAP. Cardiopulmonary function in fibrodysplasia ossificans progressiva. Thorax 1981;36:419-23.

21 Shaw MW, Falls HF, Neel JV. Congenital aniridia. Am J Hum Genet 1960;12:389-415.

22 Lynas MA. Marfan's syndrome in Northern Ireland: an account of thirteen families. Ann Hum Genet 1958;22: 289-301.

Requests for reprints to Dr J M Connor, Department of Medicine, Royal Liverpool Hospital, PO Box 147, Liverpool L69 3BX. 